\section{Taking the high ground}

Richard Dawkins

Arguments on Evolution: A Paleontologist's Perspective. By Antoni Hoffman. Oxford University Press: 1989. Pp. 274. £22.50, \$29.95.

"THIs is a book of unabashed criticism." Thus Hoffman begins his preface. I take the allusion, even if nobody else does. But if I had been writing the book, I'd have opened with a different reference:

Bring the balloon of the mind

That bellies and drags in the wind

Into its narrow shed.

Macroevolutionary studies in recent years have been dominated by what its opponents might call the windbag school of palaeontology. Now Antoni Hoffman hits back on behalf of what his opponents might call the killjoy school.

The windbag school gets its name, of course, from the inflation of levels of explanation. It is no great achievement to notice that life is organized in a hierarchy of levels. As a matter of convenience if nothing else, we use a different language when working at the different levels, and different kinds of people tend to work there. Among evolutionists macroevolution is the natural domain of palaeontologists, microevolution lies in the province of ecological geneticists. But is it just a difference of convenience or are there wholly different phenomena peculiar to the level of macroevolution? It had been the elegant conclusion of G.G. Simpson and his colleagues of the modern synthesis that macroevolution is simply what you get when you let microevolution go on for a sufficiently long time - which means a very very long time indeed. But others have wished to invoke wholly new explanatory principles for macroevolution, principles that cannot be derived by extrapolation from microevolution.

There are respectable precedents for invoking new kinds of explanation at higher levels. When we are trying to understand how certain kinds of complicated mechanisms work, for instance computers or nervous systems, it is the only way to proceed. It is true that computers work by changing the patterns of $1 \mathrm{~s}$ and $0 \mathrm{~s}$ (high and low voltage) in a large array of semiconductors, but when you've said that you haven't said anything very helpful. If you want to understand how your Macintosh actually achieves the feat of, say, shrinking a window, talk of intercutting 1s and $0 \mathrm{~s}$ isn't going to help you much. You need a higher level of explanation, a 'toolbox' of software procedures calling other procedures down through a hierarchy. This is not wanton inflation of levels of explanation; it is a dire necessity.
But what is true for computers doesn't have to be true for evolution. Time is a continuum. Aeons really are no more than milliseconds laid end to end. It is entirely possible that the processes that operate on a timescale of years, if accumulated over a sufficiently large number of years, will add up to the processes that palaeontologists pick up as macroevolution. I find it a noble, awesome thought that this might be so, like the thought that the Scottish Highlands were once as high as the Alps but have been ground down by erosion too slow to be picked up during a human lifetime. But computers and brains are noble and awesome too. Is macroevolution, as a matter of fact, like a computer or like the Highlands? This is not a question that can be decided by rhetoric. A detailed, of all the evidence is what we need, and that is what Hoffman gives us. A wellconstituted and conscientious Royal Commission on the subject would produce a report very like Hoffman's book. His verdict is a decisive victory for the Highlands over the computer. 'Megaevolution' is what you get when macroevolution has been going on for sufficiently long, macroevolution is what you get when microevolution has been going on for sufficiently long, and microevolution is what you get when individual generations have been succeeding one another for sufficiently long.

So, is Hoffman really a killjoy? That depends on where you find your joy. It is true that he takes his balloon-humbling needle from one to another of a whole range of fashionable and charismatic meticulous, intelligent, critical assessment

targets: punctuated equilibria, species selection, the decoupling of macroevolution, large-scale patterns of diversification of life on Earth, rhythmical mass extinction, and Nemesis, the postulated sister star of the Sun. These are all fun to lecture on, and they make popular bite-sized undergraduate essay topics. But there is something noble, if austere, in the attempt to explain everything in terms of a very few basic principles working on different time scales. Conjuring new 'levels of explanation' out of hats all up and down the ladder of life seems, by contrast, unimaginative, fussily ad hoc.

But there we are, back with rhetoric. What finally matters is what is true. Hoffman is short on rhetoric, long on concern for truth. He is scrupulously fair to his opponents, in many cases giving a clearer and more fully worked-out account of their theories than they do themselves. This raises our confidence in his demolition when it comes. I am not claiming that

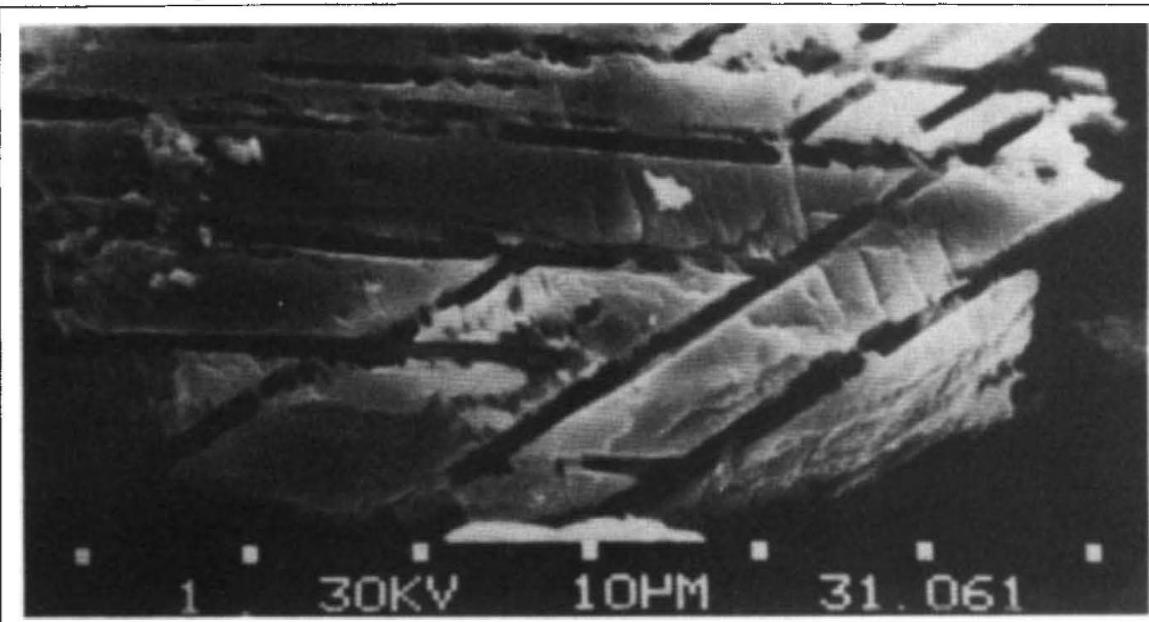

Evidence of impact - micrograph of a shocked-quartz grain from the iridium-rich layer at Brownie Butte. Montana. The picture is reproduced from Mass Extinctions: Processes and Evidence, edited by Stephen Donovan and published recently by Belhaven, London.

the last word has been said. Hoffman himself is careful to stress that his case is based only on the evidence at present available. $\mathrm{He}$ is not an ideologically committed, doctrinaire darwinian but a darwinian whose conviction comes from exhaustive examination of the evidence. Incidentally, although the idea of mass extinction is one of Hoffman's targets, there is nothing remotely anti-darwinian about mass-extinction, unlike species selection and 'decoupling'. I myself should not be surprised if Nemesis, or something equally catastrophic, one day returns to visit us. If it does, the extinction toll may include 90 per cent of all species on this Earth, but darwinism itself will not be a casualty. It will scarcely even pause before getting back down to the slow, uniformitarian grind and filling the vacuum.

Richard Dawkins is a University Lecturer in the Department of Zoology, University of Oxford, South Parks Road, Oxford OX1 3PS, UK, and a Fellow of New College. 